\title{
A importância da polêmica sobre as relações entre Marx, filosofia e método
}

\author{
Ester Vaisman $^{1}$
}

Desde logo, é imperioso ressaltar que o nosso objetivo aqui não é o de esgotar o polêmico tema que dá nome ao presente artigo, mas, antes de tudo, chamar atenção para alguns pontos, que talvez, até hoje, não tenham sido levados devidamente em consideração nas acirradas disputas teóricas sobre o caráter da relação entre Marx, filosofia e método.

Como é sabido, de acordo com Marx, as coisas do mundo humano têm elas mesmas um sentido imanente, portanto, o método aqui tem a função de buscar e captar esse sentido. A razão, em contrapartida, entendida como uma figura histórica e socialmente constituída, reproduz esse mesmo sentido. É, portanto, reprodutora de sentido e nunca sua usina originária, como ocorre na atualidade em que vivemos, no interior de um verdadeiro imperialismo da subjetividade. O objeto é passado enquanto concreto a uma forma de pensamento, vale dizer, não é o pensamento que dá forma ao objeto, recortando-o na pletora caótica do mundo fenomênico. Já em artigo de finais de 43, Marx se posiciona a respeito, ao demonstrar os limites da crítica à religião operada por Feuerbach, Marx afirma que a "missão da filosofia a serviço da história/.../ consiste em desmascarar a auto-alienação em suas formas profanas"2.

Em Teorias da Mais-Valia, por exemplo, tem-se a presença dessa mesma posição num momento mais adiantado do itinerário intelectual de Marx. Criticando James

1. Professora do Departamento de Filosofia da UFMG.

2. Karl Marx, "Crítica da filosofia do direito: Introdução" In: Temas de Ciências Humanas, Editorial Grijalbo, São Paulo, 1972, p. 2. 
Mill, que pretende conferir a Ricardo coerência lógica, formal, é afirmado o que se segue: "a contradição entre a lei geral e os desenvolvimentos concretos têm de ser feita por meio da descoberta dos elos intermediários". Ademais, prossegue, Mill erra ao pretender a "subsunção direta e o ajustamento do concreto ao abstrato"3.

Em outros termos, é um erro afirmar o movimento autônomo dos conceitos, regidos simplesmente por sua lógica interna. O procedimento correto é o movimento que vai do abstrato ao concreto pela descoberta das determinações intermediárias do próprio movimento concreto. Tais elos intermediários devem ser considerados como elos de especificação, produzidos pela própria realidade e ainda não conhecidos, mas passíveis de cognição.

Reconhecendo o caráter operativo da razão, em Marx, no entanto, a razão não comparece como critério de si mesma, pois, deixada a si - especula - o que é também por seu turno uma determinação histórica - acabando por acolher, quando busca dar a encarnação do finito - as mazelas deste $e^{4}$.

Trata-se, em verdade, de uma nova concepção de objetividade, que não guarda nenhum parentesco nem com a solução kantiana, nem com a hegeliana. Em palavras bem simples e diretas - como convém em determinados momentos -, não se trata de organizar o mundo pela cabeça, mas organizar a cabeça pelo mundo.

A organização do mundo pela cabeça, pela razão, pelo entendimento ou coisa que o valha, seja em que variante for - de Kant a Husserl - pode ser feita de vários modos; em todas, no entanto, restará algo de fora do mundo - seja o noumenon ou uma opacidade intransponível, e a cabeça organiza o mundo apenas em parte, restando ela própria limitada.

Marx reivindica a organização da cabeça regida pelo mundo, mas não o mundo das notas ou manchas empíricas, mas como todo existente e significado por si porque é (não discuto aqui a questão da gênese). O pensamento deixa de falar sobre si mesmo para falar sobre as coisas, ou seja, deixa que as coisas "falem" e "façam" o pensamento, pois este, em Marx, é histórica e socialmente constituído, como aludimos acima. Nesse sentido, a razão é transcendida pelo mundo, condiciona a visão sobre ele, porque é condicionada antes pelo próprio mundo. Ou melhor, nesse processo, ora transcende, ora é transcendida - condiciona por ter sido condicionada, isto é, quando o faz, já o faz como resultado. Atente-se que, para Marx, qualquer

3. Karl Marx, Teorias da mais-valia, São Paulo, DIFEL, 1985, t.III, p. 1142.

4. A esse propósito ver Miséria da filosofia.

10 A importância da polêmica sobre as relações entre Marx, filosofia e método 
disjunção aqui é uma forma de renúncia da razão histórica e a formas pelas quais ela pode ser edificada.

Quero ressaltar ainda, passando para outro item, mas que guarda relação direta com o anterior, que a contraposição que podemos encontrar em Marx, bem entendido, não é entre ciência e filosofia, como querem alguns, mas a contraposição entre "saber" especulativo e saber da transformação. Ou seja, um saber que saiba das coisas, para que estas possam ser alteradas, portanto, não é uma ciência anormativa, digamos, que ele reivindica por várias vezes e em vários momentos de sua obra. Poderíamos dizer que Marx, assim, se move, no campo originário de significação da filosofia, enquanto amor (carência) de saber. Portanto, em lugar do saber, da filosofia especulativa, temos o saber, a filosofia transformadora.

Assim, a eliminação pura e simples da filosofia do pensamento marxiano, e definição também pura e simples por uma ciência, a aproximação de alguma versão kantiana do conhecimento, ou seja, a substituição - de novo - pura e simples da complexa questão da causalidade, substituindo-a, de algum modo, pela mera interligação empírico/analítica da convergência ou não da empiria, acaba por desobrigar da revolução; esta passa a ser um mero apelo desiderativo e não uma necessidade real.

Num mundo inamovível e onde graça a inamovibilidade, esta desobrigação conforta, um reconforto utópico subjetivo. Em outras palavras, quando o mundo parece incapaz de se mexer e, em grande medida não se mexe, a única coisa que se agita é o espírito. Aqui o espírito volta a ser a revolução do mundo, tal como os neohegelianos de quem Marx nos fala criticamente não apenas em A Ideologia alemã, mas também, como é sabido, em outras obras do mesmo período.

Mas, retornando ao tema central do argumento, depois desse necessário volteio, gostaria que ficasse claro que tenho para com a metodologia marxiana uma antiga preocupação, cifrada, grosso modo, na dupla convicção de que se trata de um assunto decisivo, e de que é imperioso saldar um antigo débito: atingir a elevação de seu tratamento global e sistemático.

Não será ainda, é óbvio, desta vez. E não se trata de mera e simples limitação de fôlego ou de tempo. Para além disto, - é fato - que assumo como claro, trata-se da reconhecida complexidade da questão que, ao longo do tempo, só fez complicar-se.

Da promessa não cumprida de Marx, de um dia "escrever um breve estudo sobre a lógica de Hegel", a nossos dias medeia mais de um século de interpretações, imputações, polêmicas, ataques, contra-propostas, simbioses e tenebrosas simplificações, 
que acabaram por tomar conta deste espaço de investigação, a tal ponto que se tornou quase assustador nele adentrar, implicando, acima de tudo, numa postura irredutivelmente ambígua, feita de cautela e ousadia.

Bem, dito isso, tomemos para exame algumas referências diretas da obra de Marx em momentos diversos de seu itinerário intelectual: na X Tese Ad Feuerbach temos explicitamente que:

O ponto de vista [perspectiva, ponto de observação] do velho materialismo é a sociedade civil (bürgerliche Gessellschaft); o ponto de vista do novo é a sociedade humana (menschliche Geesellschaft) ou a humanidade social (gesellschaftliche Menschheit). ${ }^{5}$

Tomemos agora a IX Tese por alguns instantes; nela é caracterizado o teor e os limites do ponto de vista da sociedade civil:

O máximo (Das Höchste) a que chega o materialismo intuitivo (anschauende) [contemplativo, empírico], isto é, o materialismo que não apreende o sensível como atividade prática (praktische Tätigkeit), é a intuição (Anschauung) dos indivíduos isolados [singulares] (einzelnen Individuen) e da sociedade civil (bürgerliche Gesellschaft). ${ }^{6}$

O que se tem aqui a comentar de modo brevíssimo:

1) O ponto de vista, a perspectiva, o ponto de observação, ou seja, a posição, a base ou plataforma é referida pelo termo Standpunkt, no qual temos o pretérito de stehen, isto é, estar de pé;

2) Donde a posição do velho materialismo é a apreensão ou tem por base os indivíduos isolados - as singularidades tomadas uma a uma - e enquanto tais presentes na sociedade civil, lugar onde se defrontam. Isto é, sem apreender a gênese histórica das individualidades e da sociedade civil, não apreende a individualidade humana pela interatividade dos singulares, não alcança a individualidade social. Por isso em Feuerbach indivíduo e essência humana são naturais, "pressupondo um indivíduo humano abstrato, isolado" e "a essência só pode ser compreendida

5. Karl Marx- Frederich Engels, Ausgewälte Schriften,Berlim: Dietz Verlag, 1976, vol. II, p.526.

6. Idem, ibidem p.527

12 A importância da polêmica sobre as relações entre Marx, filosofia e método 
como 'gênero', como generalidade interna, muda, que liga de modo natural os múltiplos indivíduos”. (Teses VI e Íl)?

Ter por base indivíduos isolados que se defrontam - é partir da sociedade civil, ou seja, acriticamente, da ordem humano-societária do capital, sem compreender que esses indivíduos isolados são um produto da história, e "não sujeitos independentes por natureza", que são tomados "como um ideal, que teria existido no passado", ou seja, enquanto expressão do "naturalismo que é a aparência das robinsonadas /.../ uma antecipação da sociedade burguesa"8.

Ao passo que o materialismo marxiano, o materialismo genético, processual ou histórico, o materialismo histórico imanente parte do sujeito e objeto enquanto atividade sensível, parte da interatividade sensível dos indivíduos, parte do trabalho, por isso da "sociedade humana" ou "humanidade social", isto é, da humanidade como sociabilidade, para a qual essas duas dimensões são indissociáveis.

Em suma, o ponto de vista do velho materialismo é a visão dos indivíduos isolados se contrapondo na arena de contradições da sociedade civil, ou seja, a sociabilidade é universalizada como o lugar dos confrontos e choque de interesses particulares dos indivíduos, ou seja, a sociedade é um conjunto contraposto à individualidade, a sociabilidade é exterior à individualidade; numa palavra, no velho materialismo, indivíduo e sociedade são extrínsecos e contrapostos.

Ao passo que, no novo materialismo reivindicado por Marx, humano e social constituem uma relação fundante, só há homens em sociedade, e são as formas desta que constituem a essência dos homens: "a essência humana não é uma abstração inerente ao indivíduo singular. Em sua realidade, é o conjunto das relações sociais" (Tese VI).

Numa palavra, "... o ser dos homens é o seu processo de vida real"9.

Tomemos agora alguns fragmentos de O Capital, bastante conhecidos, mas, na maioria das vezes com alguns problemas de tradução que podem vedar o acesso ao espírito da letra marxiana. Além disso, é imprescindível observar que as características principais das afirmações que se seguem guardam estreita relação com a crítica dirigida à filosofia especulativa já em meados de 1843, como fizemos questão de ressaltar no início de nossa exposição:

7. Idem, ibidem p.527 e p. 526.

8. Karl Marx, "Introdução de 1857" In: Manuscritos econômico- filosóficos e outros textos escolhidos. Coleção Os

Pensadores, vol.XXXV, São Paulo, Abril Cultural, 1974, p.109

9. Karl Marx \& Frederich Engels, A ideologia alemã, Ed. Presença/Martins Fontes, Lisboa, 1974, p. 25.

A obra teórica de Marx e o marxismo

cadernos cemarx, n-0 3-2006 13 
Por seu fundamento (Grundlage) meu método dialético não só se diferencia do hegeliano, mas também é seu oposto direto (direktes Gegenteil). Para Hegel, o processo de pensamento, que ele, sob o nome de idéia, transforma num sujeito autônomo, é o demiurgo do real, real que constitui apenas a sua manifestação externa. Para mim, pelo contrário, o ideal não é nada mais que o material, transposto e traduzido na cabeça do homem. ${ }^{10}$

Note-se que "método dialético" não diz respeito a qualquer observação de caráter simplesmente cognitivo, mas a modos de conceber o real e o pensamento: - quem é o demiurgo de quem? "Método dialético" pode ou deve ser compreendido não pela letra da expressão, mas por seu conteúdo, como posição dialética, e enquanto tal como duas posições opostas: a de Hegel e a de Marx.

A seguir, confirma a Crítica de Kreuznach e desenvolve a argumentação: "Há quase trinta anos (janeiro de 73/meados de 43), numa época em que ela ainda estava na moda, critiquei o lado mistificador da dialética hegeliana"11.

Essa afirmação de Marx endossa a crítica à especulação contida naquele texto primígeno. Especulação para Marx significa, antes de qualquer coisa, converter o pensamento em "demiurgo do real", modo pelo qual este é reduzido a ser apenas a "manifestação externa do pensamento", isto é, aqui está em jogo uma questão ontológica fundamental - o que é o verdadeiramente real, as coisas ou o pensamento? e não um dilema metodológico. E a resposta marxiana, como é evidente, não deixa margens para dúvidas. E a frase prossegue, narrando:

Quando elaborava o primeiro volume de O Capital, epígonos aborrecidos, arrogantes e medíocres que agora pontificam na Alemanha culta, se permitiam tratar Hegel / .../ como um cachorro morto. Por isso, confessei-me abertamente discípulo daquele grande pensador e, no capítulo sobre o valor, até andei namorando (kokettierte) aqui e acolá os seus modos peculiares de expressão./.../ A mistificação que a dialética sofre nas mãos de Hegel não impede, de modo algum, que ele tenha sido o primeiro a expor as suas formas gerais de movimento, de maneira ampla e consciente. Em Hegel a

10. Karl Marx, Posfácio à Segunda Edição de O Capital, São Paulo: Abril Cultural, p. 20 e Berlim: Dietz Verlag, p.27.

11. Idem, ibidem.

14 A importância da polêmica sobre as relações entre Marx, filosofia e método 
dialética está assentada (repousa, está posta) sobre a cabeça (Sie steht bei ihm auf dem Kopf). ${ }^{12}$

É importante notar que na edição da Abril Cultural a última frase foi eliminada e na edição da DIFEL/Civilização Brasileira comparece na tradicional e distorcida versão pela qual temos que "Em Hegel, a dialética está de cabeça para baixo". - Essa última versão simplesmente toma a frase como metáfora, apontando abstrata e simplesmente para uma inversão, sem dizer do que consiste e qual é sua natureza, o que é feito pela eliminação do conteúdo preciso da frase, qual seja - a de que a dialética hegeliana é uma dialética da cabeça, ou baseada na cabeça, do ou baseado no pensamento, razão, faculdade de pensar, entendimento etc. Vale dizer, Marx não se refere de imediato a uma inversão, mas aponta ou denuncia antes, criticamente, o caráter, ou melhor, o elemento do qual é extraída. Melhor ainda, diz que a dialética hegeliana, repousando sobre a cabeça, seria uma exposição das "formas gerais do movimento do pensamento", e enquanto tal se apresenta sob invólucro mistificado. Na seqüência de seu raciocínio é que aparece uma proposta de inversão, não propriamente uma constatação de inversão: "É necessário virá-la, para descobrir o caroço racional dentro do envoltório místico" (Man muß sie umstülpen, um den rationellen Kern in der mystischen Hülle zu entdecken)"13.

Passar da cabeça às coisas, eis a proposta de inversão; não se trata de fazer inversões na dialética hegeliana, mas passar da plataforma do pensamento à plataforma das coisas para descobrir o caroço racional na dialética de Hegel; não é uma proposta de correção da dialética hegeliana para a passagem do ideal para o material e real, mas a partir deste pode-se atinar com o caroço racional daquela: pelo estudo das coisas se encontra o coágulo racional da lógica hegeliana, ou seja, "as formas gerais do movimento", porque "no entendimento positivo do existente /.../ [se] apreende cada forma existente no fluxo do movimento" - ou seja, quando se apreende o movimento das coisas pode-se expor "as formas gerais do movimento". De modo que o que Hegel supõe sejam os movimentos da idéia, nada mais são do que os movimentos gerais das coisas, que ele expõe de modo mistificado, lógico, especulativo. Essa mistificação, logicismo ou especulatividade está em supor que seja do pensamento aquilo que é

12. Idem, ibidem p.21.

13. Idem, ibidem.

A obra teórica de Marx e o marxismo

cadernos cemarx, n-3-2006 15 
das coisas, dos seres. A inversão exigida por Marx é, portanto, de ordem ontológica. E o verdadeiro território ôntico se deixa ver pelos apontamentos da seqüência da exposição marxiana:

Em sua forma mistificada, a dialética foi moda alemã, porque ela parecia glorificar o existente. Em sua configuração racional é um incômodo e um horror para a burguesia e para os seus porta-vozes doutrinários, porque, no entendimento positivo do existente (positiven Verständnis des Bestehenden), ela inclui ao mesmo tempo o entendimento da sua negação, da sua desaparição inevitável; porque apreende cada forma existente no fluxo do movimento, portanto também com seu lado transitório; porque não se deixa impressionar por nada e é, em sua essência, crítica e revolucionária. ${ }^{14}$

Note-se aqui a emergência da concepção de ser em sua dinâmica processual, origem, desenvolvimento que desemboca em sua "desaparição inevitável", ou seja, em sua morte. Desaparição por conta da própria lógica ou dinâmica das coisas, não por um pretendido movimento dissolutor da consciência enquanto dialética negativa ${ }^{15}$.

No que diz respeito às relações entre conceito e categoria no universo do pensamento de Marx, é necessário aduzir algumas palavras a respeito, baseadas, principalmente, - mas não só - em importantes passagens da chamada Introdução de 57, quando Marx, ao examinar criticamente o método da Economia Política, nos fala da necessidade do "caminho de volta", inexistente, é claro, no procedimento dos economistas ingleses. Ademais, é bom lembrar que nesse mesmo escrito Marx volta a falar também criticamente da posição especulativa hegeliana, ao salientar que:

No primeiro método [o dos economistas E.V.], a representação plena volatiza-se em determinações abstratas, no segundo [o caminho de volta E.V.], as determinações abstratas conduzem à reprodução do concreto por meio do pensa-

14. Idem, ibidem.

15. 0 ser, portanto, não é eterno, nem imutável como na metafísica - substância aristotélica. É interessante observar que o "ser para a morte" é a exageração ou absolutização do momento de extinção do ser mutável; nessa transgressão é conferida ao ser uma essência de algo quando já não é ser; o ser é destacado pelo momento em que deixa a forma de - ser, de ser humano, regredindo na escala do ser; o ser é ser pelo seu devir em não-ser. Em Hegel vai-se do nada ao ser; em Heiddegger, do ser ao nada.

16 A importância da polêmica sobre as relações entre Marx, filosofia e método 
mento. Por isso é que Hegel caiu na ilusão de conceber o real como resultado do pensamento que se sintetiza em si, se aprofunda em si, e se move por si mesmo; enquanto que o método que consiste em elevar-se do abstrato ao concreto não é senão a maneira de proceder do pensamento para se apropriar do concreto, para reproduzi-lo em concreto pensado. Mas este não é de modo nenhum o processo da gênese do próprio concreto. ${ }^{16}$

Levando em conta tais considerações, poderíamos afirmar a título de uma breve aproximação que:

1) o conceito, de um lado, afirma, estabelece, põe uma determinação; opera pois uma representação.

2) Simultaneamente, o conceito se mantém como abstração, isto é, incompleto, aberto assim, para se articular com outros conceitos, formando assim, permitindo assim, ou ainda, "pedindo" assim, o concurso de outros conceitos com os quais forma então um feixe de abstrações que possui a função da determinação, da especificação. Tal abertura e articulação não são "livres", ou caóticas. O processo aqui é conjunto dos momentos aproximativos e o ordenamento remete à matrização do ser que ele busca tornar um "concreto pensado".

Na medida em que cada categoria é, pois, ao mesmo tempo, determinação e abstração, isto é, conteúdo limitado e aberto, não é, pois, definição ( no sentido de limitar e fechar), mas é determinação que limita e abre: abre para - ganhando novo conteúdo - ser novamente limitada. Enquanto relações conceituais passam a ser indiscerníveis: concretam pelo conceito o concreto real. Sem esse tipo, por assim dizer, de mútua flexibilidade não pode haver concreção. Estão eliminados, portanto, quaisquer tipos de conceito/categoria ou procedimento formais. É evidente que se o método de que nos fala Marx é o método da concreção, suas categorias ou conceitos deverão mostrar-se capazes de promover esse processo determinativo e especificador, impensável enquanto combinatória de noções abstratas. De sorte que o dado empírico é dado para a superação pelo processo determinativo e especificador (a concreção) e não para ser enquadrado pela noção formal. A abstração aqui compreendida é o primeiro momento da concreção, não é um contorno fixo, mas um nódulo elementar pronto a se transfigurar no roteiro especificador, singularizador, o da concreção, como já foi

16.Karl Marx, op. cit. pp. 122-23.

A obra teórica de Marx e o marxismo

cadernos cemarx, n-3-2006 17 
assinalado acima. Não acolhe, por via de conseqüência, e nem é posta para acolher os dados empíricos, mas é posta como ponto de partida significativo, fundindo-se com novas determinações que vão sendo extraídas e estabelecidas a partir do próprio real. Vale dizer, não se trata de um procedimento regido por regras formais ou por uma normatividade arbitrária.

Portanto, método é meio, razão porque, diante de cada objeto, tem de ser edificado ${ }^{17}$.

Em suma, o pensamento de Marx não é um modelo, pois seu itinerário filosóficocientífico é a apreensão da lógica objetiva dos seres e processos, é a concreção conceitual da regência imanente das existências, e não a logificação da pletora fenomênica pela adjudicação a ela de um nexo exterior a ela adredemente construído, não importante aqui se este construto seja uma inferência a partir de uma saturação empírica, face à qual, na seqüência, se independentiza.

17. José Arthur Giannotti, “O Ardil do trabalho” In: Exercícios de filosofia, São Paulo, Seleções Cebrap 2,1972, p.118.

18 A importância da polêmica sobre as relações entre Marx, filosofia e método 